\title{
Variation in Incidence and Severity of Injuries among Crown-of-Thorns Starfish (Acanthaster cf. solaris) on Australia's Great Barrier Reef
}

\author{
Vanessa Messmer *, Morgan Pratchett and Karen Chong-Seng \\ Australian Research Council Centre of Excellence for Coral Reef Studies, James Cook University, Townsville, \\ QLD 4811, Australia; morgan.pratchett@jcu.edu.au (M.P.); karen.mcs@gmail.com (K.C.-S.) \\ * Correspondence: vanessa.messmer@gmail.com; Tel.: +61-7-4781-5531 \\ Academic Editors: Sven Uthicke and Michael Wink \\ Received: 8 December 2016; Accepted: 10 February 2017; Published: 21 February 2017
}

\begin{abstract}
Despite the presence of numerous sharp poisonous spines, adult crown-of-thorns starfish (CoTS) are vulnerable to predation, though the importance and rates of predation are generally unknown. This study explores variation in the incidence and severity of injuries for Acanthaster cf. solaris from Australia's Great Barrier Reef. The major cause of such injuries is presumed to be sub-lethal predation such that the incidence of injuries may provide a proxy for overall predation and mortality rates. A total of 3846 Acanthaster cf. solaris were sampled across 19 reefs, of which 1955 (50.83\%) were injured. Both the incidence and severity of injuries decreased with increasing body size. For small CoTS $(<125 \mathrm{~mm}$ total diameter) $>60 \%$ of individuals had injuries, and a mean $20.7 \%$ of arms ( $\pm 2.9 \mathrm{SE}$ ) were affected. By comparison, $<30 \%$ of large ( $>450 \mathrm{~mm}$ total diameter) CoTS had injuries, and, among those, only $8.3 \%$ of arms $( \pm 1.7 \mathrm{SE})$ were injured. The incidence of injuries varied greatly among reefs but was unaffected by the regulations of local fisheries.
\end{abstract}

Keywords: predator removal hypothesis; sub-lethal predation; arm damage; body size

\section{Introduction}

Predation has long been considered a key process in population regulation [1], contributing to long-term stability in the abundance of prey species. By inference, organisms that exhibit rapid and pronounced increases in abundance (often termed outbreaks; [2]) are considered to be released (or otherwise free) from predatory regulation (e.g., [3,4]). Predation may nonetheless be an important and often major cause of mortality but simply has no discernable influence on prey abundance [5]. Population outbreaks of prey species may occur when predators fail to react to increases in prey densities [6]. However, population outbreaks may also arise completely independently of predation, due to intrinsic and extrinsic processes. Most notably, outbreaks may result from steep changes in rates of population replenishment, especially where organisms have exceptional reproductive potential but generally low fertilisation rates and reproductive success [7]. Moreover, the abundance and reproductive success of outbreaking species is often influenced by marked changes in environmental conditions and resources (e.g., food availability) [8].

Crown-of-thorns starfish (CoTS; Acanthaster spp.) have gained considerable notoriety due to their propensity for population outbreaks, as well as their corresponding impacts on local assemblages of prey corals [9]. Very few marine organisms show changes in abundance of the magnitude or rate shown by crown-of-thorns starfish. In the extreme, 10-fold increases in localised (within reef) densities of CoTS have been documented within one year (e.g., [10]). In Moorea (French Polynesia), CoTS densities ranged from 11,500 individuals per $\mathrm{km}^{2}$ to up to 151,650 individuals per $\mathrm{km}^{2}$ around 
the circumference of the reef and were both spatially and temporally variable [10]. During the course of this outbreak, coral cover declined by up to $93 \%$ in approximate accordance with the cumulative number of CoTS recorded at each location [10].

One of the foremost hypotheses put forward to account for outbreaks of Acanthaster spp. is the predator removal hypothesis, initially proposed by Endean [11]. Endean [11] noted that shell collectors had removed $\sim 10,000$ giant tritons (Charonia tritonis), leading to significant declines in their abundance in the lead up to the first major outbreak of Acanthaster sp. recorded on Australia's Great Barrier Reef. At that time, $C$. tritonis was also regarded as one of the only effective predators of CoTS [11]. There are now a large number of coral reef organisms known to prey upon CoTS during different stages of their life cycle [12], including fish and other invertebrates. These may be important in regulating the abundance of CoTS, if not in actually preventing outbreaks. Coral reef fishes that prey on CoTS are receiving particular attention [13-15], given that localised levels of fishing seem to correspond with inter-reef variation in the severity [15] or incidence [14] of CoTS outbreaks. The most intuitive explanation for these patterns is that the overexploitation of particular fishes relaxes the top-down control necessary to regulate populations of Acanthaster spp. [11], thereby leading to population outbreaks. However, these studies have not identified the specific target species that predate on CoTS nor have they explicitly compared densities of CoTS predators or quantified rates of predation of CoTS along gradients of fishing pressure. Trophic cascades induced by fisheries, resulting in fewer invertebrates preying on juvenile starfish, may be another mechanism releasing predation pressure on CoTS [14].

One of the main limitations to testing the predator removal hypothesis is the inherent difficulty in quantifying predation rates on Acanthaster spp. in the field. This is particularly difficult for small and juvenile Acanthaster spp. due to their cryptic nature [16]. One possible proxy for measuring variation (spatial, temporal, taxonomic, and ontogenetic) in the susceptibility to predation among Acanthaster spp. is the incidence of recent injuries. These are most apparent as missing or regenerating arms (Figure 1), which are often attributed to sub-lethal or partial predation [16,17]. Although sub-lethal predation is also generally considered a good proxy for mortality due to predation, or overall predation pressure [16,17], this has not been explicitly tested, and predators causing injuries may not cause outright mortality of CoTS. Relatively few predators are known to consume adult CoTS in their entirety (but see [18]), while CoTS survive and can escape from predators (e.g., fishes) that only remove a portion of the body mass [19]. In previous studies, up to $67 \%$ of CoTS in some locations exhibit recent or sustained injuries [16], and high incidences of injuries appear to be generally reflective of a higher intensity of predation [16,17]. In the Philippines, for example, Rivera-Posada et al. [16] showed that the incidence of injuries was higher inside rather than outside of marine protected areas (MPAs) where fishing is prohibited, which would be consistent with a higher abundance of potential predators. The incidence of injuries also tends to decrease with the increasing body size of Acanthaster sp. [20] as well as for several other species of starfishes [21,22], which probably reflects their increased susceptibility to predation when small [22]. Even if the predators that cause a high incidence of injuries among Acanthaster spp. do not kill these starfish outright, they may nonetheless have important effects on the behaviour and fitness of starfish, thereby contributing to population regulation [23].

The purpose of this study was to test for variation in the incidence and severity of injuries among crown-of-thorns starfish (Acanthaster cf. solaris) from Australia's Great Barrier Reef (GBR). More specifically, we wanted to test whether the incidence of injuries is higher inside versus outside MPAs, where fishing is prohibited, as would be expected if fisheries' target species impose significant predatory regulation on CoTS on the GBR and the abundance of these key predators vary significantly in accordance with spatial management zones [14]. We also tested for size-based variation in the incidence of injuries among CoTS, ranging in size from $60 \mathrm{~mm}$ total diameter (TD) to $510 \mathrm{~mm}$ TD. These injuries are presumably caused mostly by sub-lethal predation [17] (but see [22]). 


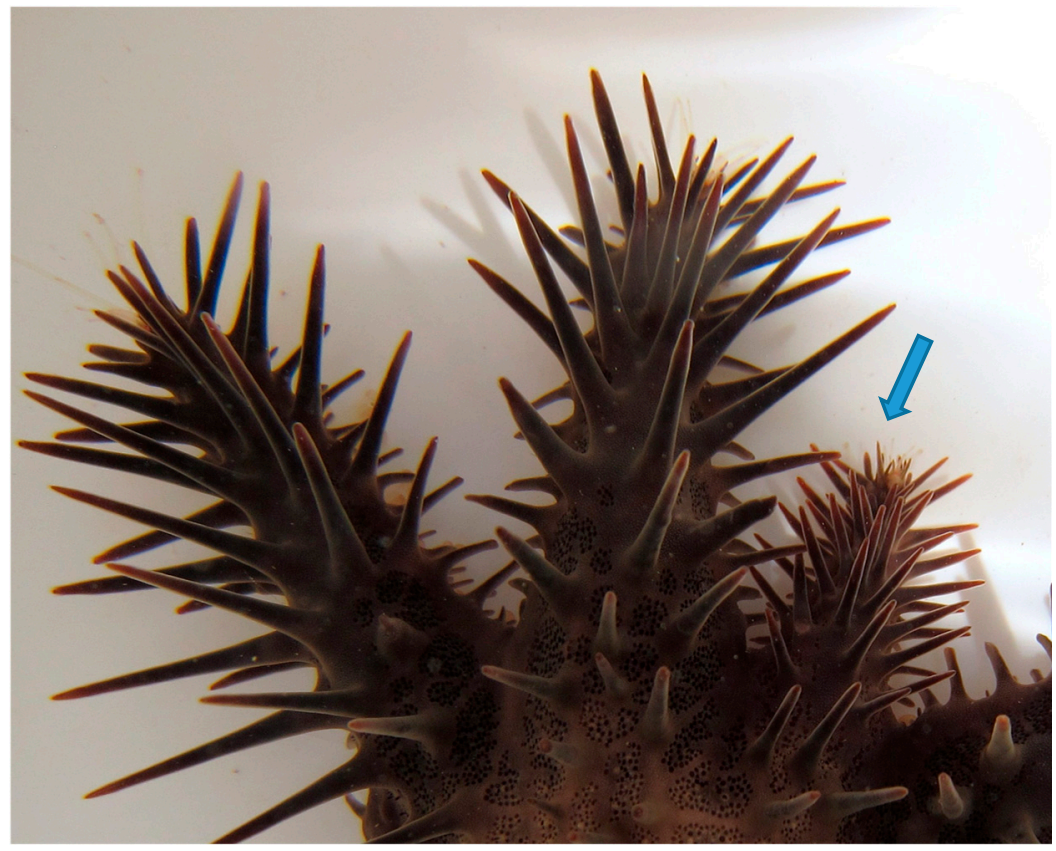

Figure 1. Small and regenerating arm of Acanthaster cf. solaris (as indicated by arrow), which is indicative of past injury, presumably caused by sub-lethal predation (see also [16]).

\section{Materials and Methods}

A total of 3846 crown-of-thorns starfish (Acanthaster cf. solaris) were collected between October 2012 and May 2015 along the Great Barrier Reef (GBR). Sampling was conducted at 19 reefs, spanning $1150 \mathrm{~km}$ of the GBR (Figure 2). All reefs, except Centipede Reef, Davies Reef, Michaelmas Cay, and Sweetlip Reef, were considered to have an active CoTS outbreak at the time of sampling. All starfish were collected while snorkelling or SCUBA diving using large purpose-built tongs to carefully extract starfish from among the reef matrix. Starfish were kept alive in $500 \mathrm{~L}$ tanks connected to high flow-through sea-water systems on live-aboard boats or at the research station on Lizard Island for a maximum of $20 \mathrm{~h}$ before they were processed and disposed. During processing, the starfish were removed from the water and placed on a flat surface for 30-90 s before measuring the total diameter across opposite arms that were ostensibly undamaged. The severity of injury was then assessed by counting the number of missing or damaged arms, which was then expressed as a percentage of the total number of arms (also referred to as "severity"). Missing arms were apparent where the ambulacral groove terminated at the edge of the oral disk. All arms that were less than $75 \%$ the length of the adjacent arms were considered to have been damaged. Recent injuries, apparent due to fresh tears in the surface integument, were ignored, as they likely occurred during collection. We also determined the sex of each individual starfish (where possible) based on visual inspection of the gonads that were exposed following the removal of a few arms using a paint scraper [9]. Starfish that were either immature or spent (virtually no gonad tissue left after spawning) could not be sexed, resulting in 1078 and 1475 individuals identified as females and males respectively.

\section{Data Analyses}

The probability of an individual CoTS being injured (injury incidence) was analysed using binary logistic mixed models (logit link), with "zone" (no fishing, restricted fishing, open to fishing) and "size" (total diameter: $\mathrm{mm}$ ) as possible influential factors. The influence of zone and size on the severity of injuries received during predation events was also investigated using a subset of the data $(n=1797)$, which only included individuals that had experienced arm damage (injury $=1)$ and was modeled as the proportion of injured arms (in relation to the total no. arms) using binomial mixed 
models (logit link). The potential influence of adult gender (male or female) on CoTS injuries was also investigated using the subset of starfish for which sex could be established ( $n=2553$ for influence on injury incidence and $n=1263$ for influence on injury severity) using generalized mixed models (logit link: binary logistic and binomial, respectively).

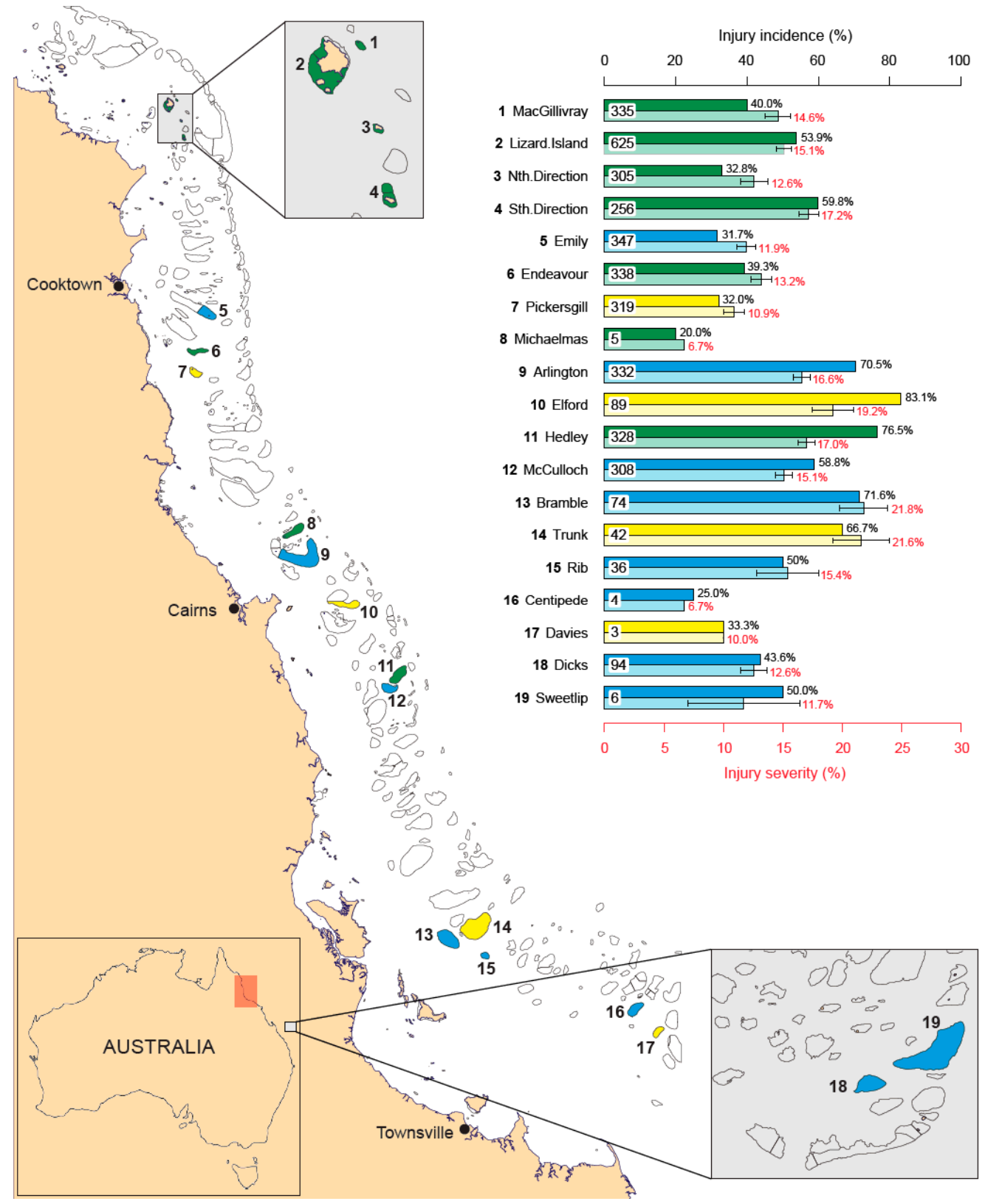

Figure 2. Map indicating sampled reefs along the Great Barrier Reef (GBR). The red box on the map of Australia shows the extent of the main map, whilst the reefs sampled in the Swains Region on the south-eastern end of the GBR are magnified in the bottom right rectangle. The colour of sampled reefs designates fishing regulations: green = no fishing (marine reserve), yellow = restricted fishing allowed, blue = open to fishing. The bar graph shows injury incidence per reef (top paired bar with solid fill and black values) and mean \pm SE injury severity per reef (lower paired bar with semi-transparent fill and red values). Numbers in the white boxes within the bars represent the total number of individuals collected per reef. Injury severity values were calculated based on injured individuals only. 
For all models, "reef" was included as a random effect (19 levels), while "observer" was included as a potential fixed effect ( 3 levels) to account for possible artifacts of the sampling design and different data collectors. Full models, with all the potential relevant interactions, were fit first, and then model selection procedures were applied, comparing models using likelihood ratio tests [24,25]. The model assumptions were checked graphically, investigating residuals and random effects before interpretation of the final model. The confidence intervals around the coefficient estimates of the final models were generated by parametric bootstrapping. All statistical analyses were conducted using the $\mathrm{R}$ statistical software program (R Core Team 2016) and the lme4 package [26].

\section{Results}

\subsection{Incidence of Injuries}

In all, 1955 out of 3846 (50.83\%) CoTS collected from the GBR exhibited evidence of recent or sustained injuries, based on the number of arms that were missing or evidently shorter and thinner and generally covered in shorter and finer spines (Figure 1). The incidence of injury varied considerably between reefs, ranging from 20\% (1 starfish injured out of 5) at Michelmas Cay near Cairns up to 83\% (74 starfish injured out of 89) at Elford Reef, also located very close to Cairns (Figure 2). The mean severity of injuries (calculated based on the percentage of arms affected) also varied among reefs, ranging from $6.7 \%$ at Centipede Reef, where only one starfish that was injured was collected, up to $21.8 \%( \pm 2.0 \% \mathrm{SE})$ at Bramble Reef. Interestingly, there was a positive linear correlation $\left(R^{2}=0.783\right.$, $p<0.001$ ) between the incidence and the severity of injuries at the scale of individual reefs (Figure 3 ).

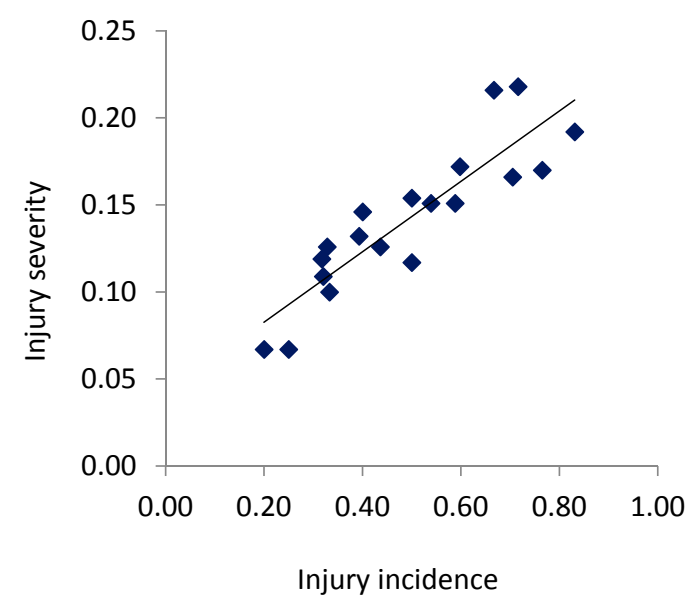

Figure 3. Linear regression $\left(R^{2}=0.783\right.$; slope $=0.2023\left(F_{(1,17)}=61.29, p<0.001\right)$; intercept is not significantly different from 0 ) between incidence (proportion of starfish with any evidence of injury) and severity (mean proportion of arms affected among injured starfish) at the scale of reefs.

Despite marked inter-reef differences in the incidence and severity of injuries, there was no obvious effect of the regulations of local fisheries (Tables 1 and 2). When averaged across all reefs in each of the three distinct management zones, the mean incidence of injury was non-significantly higher for yellow zones $(53.78 \% \pm 12.66 \% \mathrm{SE})$, followed by blue zones $(50.15 \% \pm 5.92 \% \mathrm{SE})$ and lowest in green zones $(46.05 \% \pm 7.10 \% \mathrm{SE})$. However, these differences are negligible compared to the variation observed among 'reefs' within each group, as evident based on large standard errors (Figure 4a). There was also no influence of fishing regulation (zone) in any of the models. Likelihood ratio tests with and without zone as a fixed effect can be seen in Table 1 . The frequency distributions of the number of arms missing were also very similar across the three management zones, with a single missing arm affecting the majority of injured individuals (65\%-70\%) (Figure $4 b-d)$. 

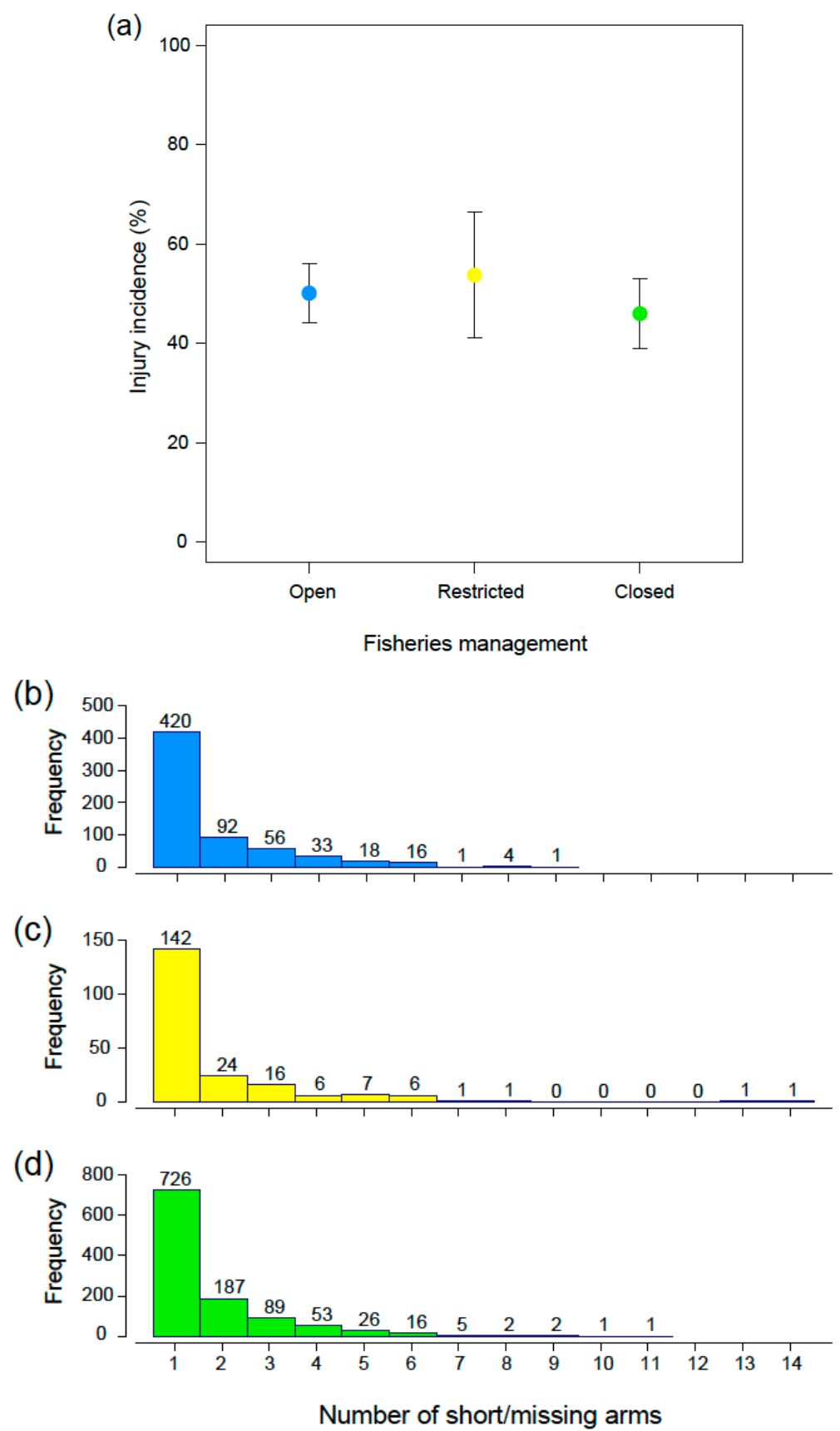

Figure 4. (a) Incidence of injury (percentage of individuals with damaged arms) averaged across the reefs in each of three different management zones (the colour of the circle designates fishing regulations: see $(\mathbf{b}-\mathbf{d}))$; and (b) frequency distributions of short or missing arms for each zone ((b) blue = open to fishing; (c) yellow = restricted fishing; $(\mathbf{d})$ green = no fishing). 
Table 1. Overview of the model selection process, starting with the full model including all relevant interactions, compared with Akaike Information Criterion (AIC) and Likelihood-ratio tests.

\begin{tabular}{|c|c|c|c|}
\hline Data & Candidate Model Effects & AIC & Likelihood Test * \\
\hline Incidence $(n=3846)$ & $\begin{array}{c}\text { Zone * Size + Observer + (1 I Reef }) \\
\text { Zone * Size + Observer + (Size I Reef }) \\
\text { Zone + Size + Observer + (Size I Reef }) \\
\text { Size + Observer + (Size I Reef })\end{array}$ & $\begin{array}{l}4937.8 \\
4935.4 \\
4933.2 \\
4930.1\end{array}$ & $C h i=1.0, d f=2, p=0.617$ \\
\hline Severity $* *(n=1797)$ & $\begin{array}{c}\text { Zone }{ }^{*} \text { Size }+ \text { Observer } \\
\text { Zone }+ \text { Size }+ \text { Observer } \\
\text { Size }\end{array}$ & $\begin{array}{l}5847.6 \\
5846.0 \\
5841.1\end{array}$ & $C h i=3.1, d f=4, p=0.541$ \\
\hline Gender (Incidence) ${ }^{* *}(n=2553)$ & $\begin{array}{c}\text { Zone }+ \text { Size } * \text { Sex }+ \text { Observer } \\
\text { Zone }+ \text { Size }+ \text { Sex }+ \text { Observer } \\
\text { Size }+ \text { Sex }\end{array}$ & $\begin{array}{l}3287.6 \\
3285.8 \\
3285.0\end{array}$ & $C h i=3.2, d f=2, p=0.204$ \\
\hline Gender (Severity) ${ }^{* *}(n=1263)$ & $\begin{array}{c}\text { Zone }+ \text { Size } * \text { Sex }+ \text { Observer } \\
\text { Zone }+ \text { Size }+ \text { Sex }+ \text { Observer } \\
\text { Size }+ \text { Sex }\end{array}$ & $\begin{array}{l}4210.1 \\
4204.1 \\
4177.2\end{array}$ & $C h i=1.2, d f=4, p=0.814$ \\
\hline
\end{tabular}

Table 2. Model coefficients for the best fitting models describing the relationship between injury incidence and severity with size, whilst accounting for the variability between the reefs in all models and observer bias for models of incidence (Figures 5 and 6).

\begin{tabular}{ccccc}
\hline Data & Variable & Estimate \pm SE & $z$-Value & $p$-Value \\
\hline \multirow{4}{*}{ Incidence } & (Intercept) & $1.0708 \pm 0.3239$ & 3.3055 & 0.0009 \\
& Size & $-0.0043 \pm 0.0009$ & -4.8358 & 0.0000 \\
& Observer2 & $1.1351 \pm 0.3793$ & 2.9929 & 0.0028 \\
& Observer3 & $-0.0872 \pm 0.3248$ & -0.2685 & 0.7883 \\
\hline \multirow{2}{*}{ Severity } & (Intercept) & $-1.3512 \pm 0.0925$ & -14.6038 & 0.0000 \\
& Size & $-0.0020 \pm 0.0003$ & -7.0685 & 0.0000 \\
\hline \multirow{5}{*}{ Gender (incidence) } & (Intercept) & $1.0882 \pm 0.3639$ & 2.9907 & 0.0028 \\
& Size & $-0.0042 \pm 0.0008$ & -5.4448 & 0.0000 \\
& Male & $-0.0343 \pm 0.0874$ & -0.3922 & 0.6949 \\
& Observer2 & $0.9585 \pm 0.3945$ & 2.4300 & 0.0151 \\
& Observer3 & $0.0255 \pm 0.3693$ & 0.0690 & 0.9450 \\
\hline \multirow{3}{*}{ Gender (severity) } & (Intercept) & $-1.1265 \pm 0.1258$ & -8.9549 & 0.0000 \\
& Size & $-0.0025 \pm 0.0004$ & -6.5331 & 0.0000 \\
& Male & $-0.0623 \pm 0.0394$ & -1.5818 & 0.1137 \\
\hline
\end{tabular}

\subsection{Size-Based Variation}

The incidence of injuries showed a negative relationship with the increasing size of CoTS $(z=-4.836, p<0.001)$ (Figure 5a). The probability of a small starfish $(60 \mathrm{~mm})$ exhibiting any level of injury was $0.70(95 \% \mathrm{CI}=[0.57,0.79]$ by parameter bootstrap $[\mathrm{PB}])$, decreasing to 0.25 $(95 \% \mathrm{~PB} \mathrm{CI}=[0.15,0.38])$ in the largest individual $(510 \mathrm{~mm})$ when observed by the median observer. Although injury incidence was affected by the observer (Tables 1 and 2), Observer identity did not influence the shape of the relationship (Likelihood-ratio tests with and without the observer influencing slope: $C h i=1.0, d f=5, p=0.959)$ (Figure 5a). The severity of injuries showed a similar decline with increasing size $(z=-7.069, p<0.001)$ (Figure $5 b)$. Small starfish (60 mm) generally exhibited injuries to $19 \%$ of their arms $[16 \%, 21 \% \mathrm{CI}]$, decreasing to $9 \%[8 \%, 11 \% \mathrm{CI}]$ in large starfish $(\sim 470 \mathrm{~mm})$. Neither the observer or the reef had any effect on the relationship between the severity of the injuries and the size of the CoTS (Figure 5b). 

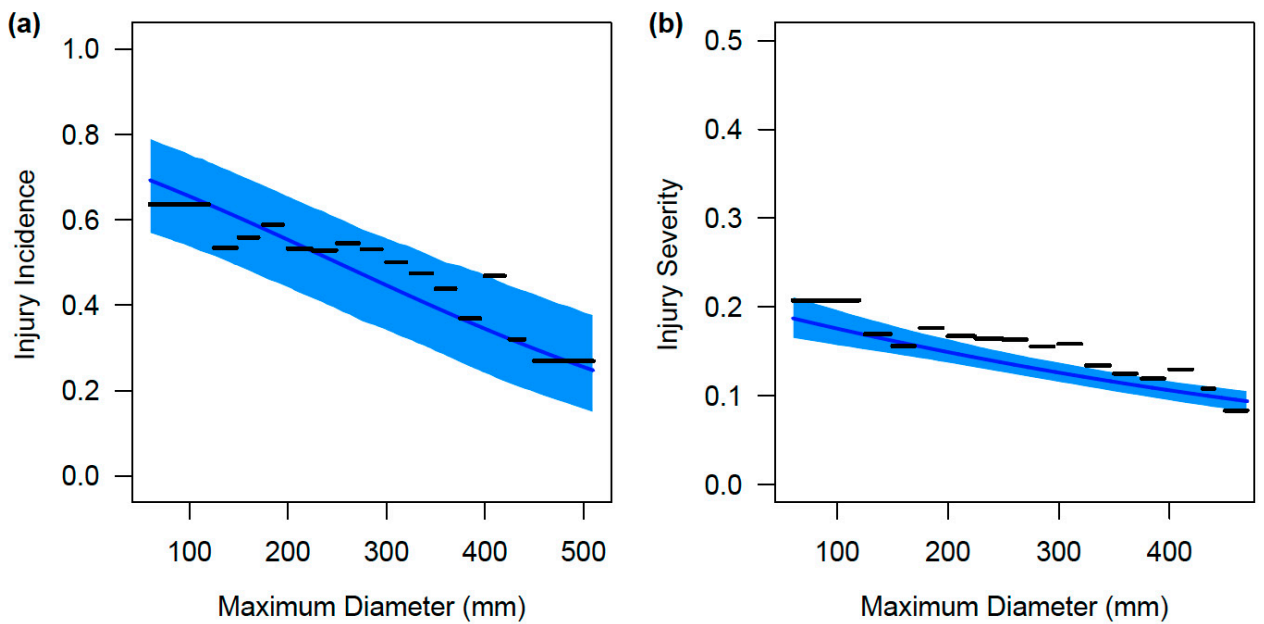

Figure 5. Relationship (with 95\% confidence intervals (CI) generated by parametric bootstrap) between (a) CoTS maximum diameter and the probability of the individual to have experienced arm damage (injury incidence; binary data), as measured by the median observer on an average reef; (b) CoTS maximum diameter and the severity of an individual's injury on an average Reef (note y-axis has been truncated to aid visualization of the relationship). Black horizontal lines represent the mean probability of individuals in $25 \mathrm{~mm}$ size classes $(<125,125-150,150-175, \ldots,>450 \mathrm{~mm})$ superimposed over the relationship.

\subsection{Gender-Based Differences in Incidence and Severity of Injuries}

Gender did not influence the incidence or severity of starfish arm damage statistically (Tables 1 and 2). Female and Male starfish incidence of arm damage was $0.64[0.49,0.77]$ and $0.63[0.49,0.76]$, respectively, when small $(\sim 125 \mathrm{~mm})$, decreasing to $0.26[0.16,0.40]$ and $0.26[0.15$, 0.40] when large $(\sim 510 \mathrm{~mm})$, respectively (Figure $6 \mathrm{a})$. However, the severity of arm damage was slightly reduced in males in comparison to females; $0.18[0.16,0.21]$ when small $(\sim 125 \mathrm{~mm})$ and $0.09[0.07,0.10 \mathrm{CI}]$ when large $(\sim 470 \mathrm{~mm})$ vs. $0.19[0.17,0.22 \mathrm{CI}]$ when small and $0.09[0.08,0.11]$ when large, respectively (Figure 6b).
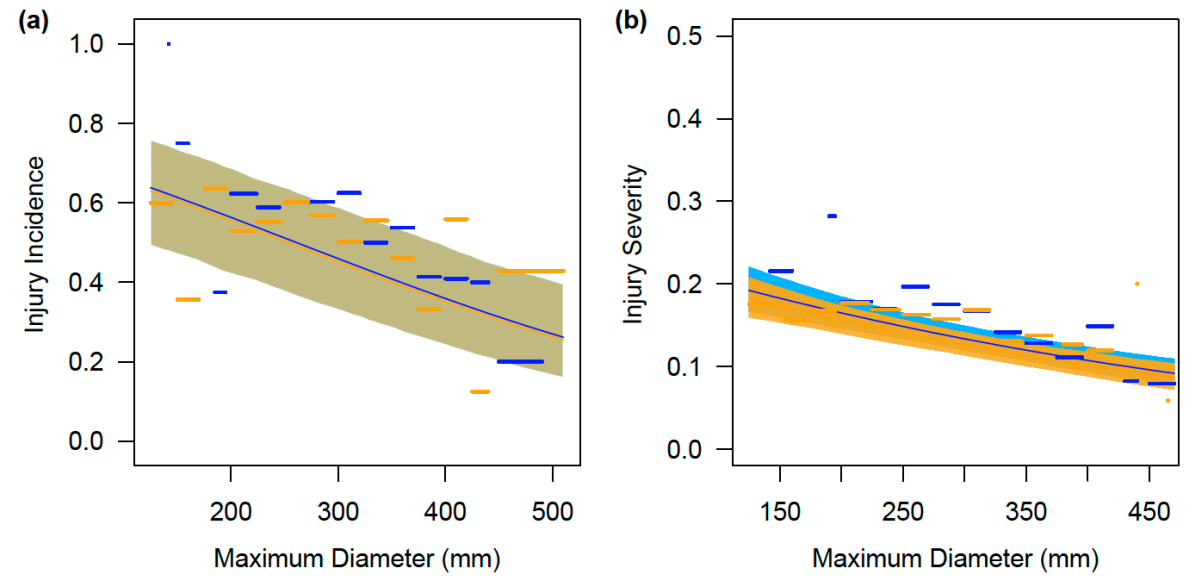

Figure 6. Relationships (with 95\% confidence intervals (CI) generated by parametric bootstrap) between female (blue) and male (orange) CoTS maximum diameter and injury (a) incidence (arm damage as measured by the median observer on an average reef; binary data) and (b) severity on an average reef. Horizontal lines represent the mean probability of female (blue) and male (orange) individuals in $25 \mathrm{~mm}$ size classes $(<125,125-150,150-175, \ldots,>450 \mathrm{~mm})$ superimposed over the relationship. Note that the $y$-axis has been truncated to aid visualization of the relationship for severity. 


\section{Discussion}

Outbreaks of Acanthaster spp. are a major contributor to coral loss and reef degradation throughout the Indo-Pacific region (e.g., $[10,27])$, and a major concern for coral reef management. Understanding the possible role of predation in regulating populations of Acanthaster spp. is fundamental in establishing whether increased regulation of fisheries will mitigate or prevent ongoing outbreaks [12]. Although the overall incidence of injury was high (50\%) amongst the CoTS sampled along much of the length of the GBR, there was no difference in the incidence or severity of injuries for CoTS from reefs where fishing is prohibited (green zones) versus reefs where fishing activities are permitted (yellow and blue zones). However, there was strong variation in the incidence of injuries among reefs, ranging from $20 \%$ to $83 \%$. There was also a strong negative correlation between body size (CoTS diameter) and arm damage, with individuals $\leq 125 \mathrm{~mm}$ in diameter being twice as likely to be injured than individuals $\geq 400 \mathrm{~mm}$. The severity of injuries (the proportion of the number of injured arms over the total number of arms) showed a very similar reduction with increasing body size. There was only a very weak gender trend, with females being slightly more likely to suffer increased arm damage (severity) than males.

Whether predators are able to regulate CoTS abundances remains the topic of ongoing debate. Across the GBR, the occurrence of CoTS outbreaks is lower on reefs where fishing is prohibited, compared to reefs where fishing is permitted $[14,28]$, which suggests that the higher abundance of large target species results in greater predation of CoTS. In the current study, fishing restrictions had no effect on the incidence of injuries, which are presumably caused mostly by sub-lethal predation [17] (but see [22]). However, even if injuries are caused mainly by predation, overall mortality and predation rates may still vary with the management of fisheries. The sub-lethal predation rate is generally considered to be a proxy for overall predation pressure [16,17], but this has not been explicitly tested. It may be that the fishes that cause injuries (loss of individual arms) are altogether different from those that kill CoTS outright, such that direct tests of the predator-removal hypothesis still require measurements of actual mortality rates alongside explicit consideration of the abundance and composition of potential predators, irrespective of zoning. Except for some lethrinid species, most other known CoTS predators (e.g., the stellar pufferfish Arothron stellatus) [12] are not generally targeted by recreational and commercial finfish fisheries on the GBR, which mainly target large piscivorous fishes such as coral trout [29].

Irrespective of whether injuries are a valid proxy for overall predation and predation rates, higher incidences and severity of sub-lethal predation will have a significant impact on the individual fitness and population dynamics of CoTS [23,30,31]. CoTS, like many other echinoderms, have the capacity to regenerate parts of their central disc and missing arms $[19,22]$. However, regeneration comes at an energetic cost and affects the fitness of individuals [31,32]. Injuries and regeneration can reduce feeding and growth, delay maturation, or compromise the reproductive output. Given that each arm contains gonads in CoTS, fewer arms directly affect the reproductive capacity of a female. In the sea star Heliaster helianthus, the energetic content in their pyloric caeca and gonads showed a 5 to 7 fold decrease following autotomy [31]. Similarly, regenerating tails in lizards were found to affect clutch and egg size [33], and maternal effects were observed in CoTS, with reduced egg size resulting in lower survivorship in developing larvae [34]. As a result, even relatively minor injuries may have considerable negative impacts on the reproductive success of individual females.

The overall incidence of injury recorded in this study $(50 \%)$ is at the higher end of rates reported previously from the GBR (33\% [35]; 40\% [17]; 50\% [36]). However, our study clearly showed that the incidence of injury varies among reefs on the GBR $(20 \%-83 \%)$, and the range of variation recorded in this study is consistent with differences in the estimates of the incidence of injuries from previous studies, all of which considered only a single or few sites. The highest incidences of injury recorded $(81.3 \%)$ on some reefs exceeded the highest reported incidence of damaged arms $(67 \%)$ recorded in the Philippines [16]. Although the observer had an effect on the incidence of arm damage, substantial variation between reefs was still clearly observed irrespective of who counted the number of short or 
missing arms. The high rates on some reefs may represent a regional effect (this could not be tested due to the covariation with the observer in some cases). The Cairns sector (Reefs 8-12, Figure 2) had above average rates (59\%-83\%), whereas the Cooktown sector (Reefs 5-7, Figure 2) had below average incidences of arm damage (32\%-39\%). The high injury rates (50\%-72\%) on reefs with outbreaks in the Townsville sector (Reefs 13-17, Figure 2) are likely to reflect the on average smaller individuals collected on these reefs. The variation in injury rates between reefs may also be due to differences in the local abundance of predators. Future studies should therefore explicitly test if there is a relationship between the incidence of arm damage and the abundance of predators.

Vulnerability to predation is known to vary with ontogeny in many organisms $[37,38]$. Younger and smaller individuals are often subject to higher predation rates than older and larger conspecifics [39-41]. Large CoTS exhibit an impressive defense against predators through the presence of large, very sharp, and poisonous spines, which may limit the number of species able to predate on large adult CoTS. It is therefore not surprising to see a $50 \%$ reduction in the incidence and severity (measured as the number of injured arms over the total number of arms) of arm damage with increasing body size (the relationship was not affected by the observers). Size has previously been identified as an important factor in predation rates in other echinoderms and CoTS, but patterns are not always consistent. Sub-lethal injuries generally decline with increasing body size in echinoderms [21], asteroids [22], sea urchins [42,43], and CoTS [16,17]. McCallum et al. [17] found a similar but weak linear relationship in CoTS, whereas a hump-shaped relationship was observed in the Philippines, which covered a similar size range as the present study [16]. Although the discrepancy between the studies could be due to sample size (both studies had relatively low sample sizes of individuals $\leq 10 \mathrm{~cm}$ ), the discrepancy may also be due to differences in local predation pressure. A reduction in arm damage in individuals $\leq 10 \mathrm{~cm}$ is possible and could be explained by behavioural changes or changes in the ratio between lethal and sub-lethal predation rates [16]. Increased sampling in these smaller size classes, including very small juvenile CoTS [44], should clarify the effect of size on sub-lethal predation rates in these early life stages. Nevertheless, the high incidence of predation rates in smaller CoTS $(\leq 20 \mathrm{~cm})$ across both studies suggests that substantial predation levels are likely to occur at night due to the nocturnal feeding habits and cryptic nature of small CoTS during the day.

There were indications that gender may have a weak effect on predation severity. Although not statistically significant, female CoTS exhibited slightly higher levels of injuries compared to males, which may be explained by the relatively higher energy content in oocytes compared to spermaries. Similarly, egg-bearers in other marine organisms were found to be more susceptible to predation, with the higher nutritional value of oocytes proposed as a mechanism [38,45]. Interestingly, there was no difference in the injury incidence between males and females, suggesting that predators do not discriminate between males and females but may feed more intensively on females.

\section{Conclusions}

Predation has the potential to play a significant role in regulating populations of CoTS, though the effect is most likely to dampen fluctuations in the local abundance of CoTS rather than to prevent outbreaks per se. Ormond et al. [13] suggested that predation levels by fish on CoTS could maintain CoTS in sufficiently low densities to avoid outbreaks. Our study showed that at least sub-lethal predation on CoTS is common, with $50 \%$ of the 3846 individuals studied showing evidence of predation events, and that size plays a major role in the frequency and severity of predation events. Although the predator removal hypothesis remains controversial, with studies showing variable results, predation of CoTS is a common event that warrants further investigation. It is critical to determine predation rates in small juveniles, identify all possible predators, and assess the effects of sub-lethal predation on growth, fitness, and reproductive output to better inform population models. There is no stopping the current outbreak on the GBR, but any attempts to prevent future outbreaks in light of the increasing threats to coral reefs is possibly our easiest chance to improve the outlook for coral reefs. 
Acknowledgments: We are grateful to Hugo Harrison, Simon Wever, Kirsty Nash, Zara-Louise Cowan, Laura Richardson, Robert Streit, Kristen Anderson, Stuart Watson, Jacob Johansen, and Elmar Messmer for their assistance in the collection of CoTS and to the Lizard Island Research Station staff, Tim Godfrey, and the crew of Reef Connections and the Capricorn Star for logistical support. This project was supported by the Commonwealth Government of Australia through the Caring for Country and Reef Rescue Program to M.P. and V.M. and the Australian Museum's Lizard Island Research Station with specific awards to M.P. and V.M from the Ian Potter Foundation 50th Anniversary Commemorative Grant Scheme.

Author Contributions: M.P. conceived and designed the experiments; V.M., M.P., and K.C-S. performed the experiments; V.M. and K.C-S. analysed the data; V.M., M.P., and K.C-S. wrote the paper.

Conflicts of Interest: The authors declare no conflict of interest.

\section{References}

1. Murdoch, W.W.; Oaten, A. Predation and population stability. Adv. Ecol. Res. 1975, 9, 1-131.

2. Carpenter, J.R. Insect outbreaks in Europe. J. Anim. Ecol. 1940, 9, 108-147. [CrossRef]

3. Holling, C.S. The functional response of predators to prey density and its role in mimicry and population regulation. Mem. Entomol. Soc. Can. 1965, 45, 5-60. [CrossRef]

4. Rosenzweig, M.L. Paradox of enrichment: Destabilization of exploitation ecosystems in ecological time. Science 1971, 171, 385-387. [CrossRef] [PubMed]

5. Stiling, P. Density-dependent processes and key factors in insect populations. J. Anim. Ecol. 1988, 57, 581-594. [CrossRef]

6. Clark, L.R. Predation by birds in relation to the population density of Cardiaspina albitextura (Psyllidae). Aust. J. Zool. 1964, 12, 349-361. [CrossRef]

7. Uthicke, S.; Schaffelke, B.; Byrne, M. A boom-bust phylum? Ecological and evolutionary consequences of density variations in echinoderms. Ecol. Monogr. 2009, 79, 3-24.

8. Singleton, G.R. Population dynamics of an outbreak of house mice (Mus domesticus) in the Mallee Wheatlands of Australia-Hypothesis of plague formation. J. Zool. 1989, 219, 495-515. [CrossRef]

9. Pratchett, M.S.; Caballes, C.F.; Rivera-Posada, J.A.; Sweatman, H.P.A. Limits to understanding and managing outbreaks of crown-of-thorns stafish (Acanthaster spp.). Oceanogr. Mar. Biol. Annu. Rev. 2014, 52, 133-199.

10. Kayal, M.; Vercelloni, J.; de Loma, T.L.; Bosserelle, P.; Chancerelle, Y.; Geoffroy, S.; Stievenart, C.; Michonneau, F.; Penin, L.; Planes, S.; et al. Predator Crown-of-Thorns Starfish (Acanthaster planci) Outbreak, Mass Mortality of Corals, and Cascading Effects on Reef Fish and Benthic Communities. PLoS ONE 2012, 7, e47363. [CrossRef] [PubMed]

11. Endean, R. Report on Investigations Made into Aspects of the Current Acanthaster planci (Crown-of-Thorns) Infestations of Certain Reefs of the Great Barrier Reef; Queensland Department of Primary Industries: Brisbane, Australia, 1969.

12. Cowan, Z.L.; Pratchett, M.S.; Messmer, V.; Ling, S. Known predators of crown-of-thorns starfish (Acanthaster spp.) and their role in mitigating, if not preventing, population outbreaks. Diversity 2017, $9,7$.

13. Ormond, R.F.G.; Bradbury, R.H.; Brainbridge, S.; Fabricius, K.; Kessing, J.K.; de Vantier, L.M.; Medlay, P.; Steven, A.D.L. Test of a model for regulation of crown-of-thorns starfish by fish predators. In Acanthaster and the Coral Reef: A Theoretical Perspective; Bradbury, R.H., Ed.; Springer: Heidelberg, Germany, 1990; pp. 189-207.

14. Sweatman, H. No-take reserves protect coral reefs from predatory starfish. Curr. Biol. 2008, 18, R598-R599. [CrossRef] [PubMed]

15. Dulvy, N.K.; Freckleton, R.P.; Polunin, N.V.C. Coral reef cascades and the indirect effects of predator removal by exploitation. Ecol. Lett. 2004, 7, 410-416. [CrossRef]

16. Rivera-Posada, J.; Caballes, C.F.; Pratchett, M.S. Size-related variation in arm damage frequency in the crown-of-thorns sea star, Acanthaster planci. J. Coast. Life Med. 2014, 2, 187-195.

17. McCallum, H.I.; Endean, R.; Cameron, A.M. Sublethal damage to Acanthaster planci as an index of predation pressure. Mar. Ecol. Prog. Ser. 1989, 56, 29-36. [CrossRef]

18. Bos, A.R.; Gumanao, G.S.; Salac, F.N. A newly discovered predator of the crown-of-thorns starfish. Coral Reefs 2008, 27, 581. [CrossRef] 
19. Messmer, V.; Pratchett, M.S.; Clark, T.D. Capacity for regeneration in crown of thorns starfish, Acanthaster planci. Coral Reefs 2013, 32, 461. [CrossRef]

20. Simpson, C.J.; Grey, K.A. Crown-of-Thorns Starfish (Acanthaster planci) in the Dampier Archipelago, Western Australia; Technical Series; Perth Environmental Protection Authority: Perth, Australia, 1988.

21. Lawrence, J.M.; Vasquez, J. The effect of sublethal predation on the biology of echinoderms. Oceanol. Acta 1996, 19, 431.

22. Lawrence, J.M. Arm loss and regeneration in Asteroidea (Echinodermata). In Echinoderm Research; Scalera-Liaci, L., Canicatti, C., Eds.; Balkema: Rotterdam, The Netherlands, 1991; pp. 39-52.

23. Harris, R.N. Nonlethal injury to organisms as a mechanism of population regulation. Am. Nat. 1989, 134, 835-847. [CrossRef]

24. Bolker, B.M.; Brooks, M.E.; Clark, C.J.; Geange, S.W.; Poulson, J.R.; Stevens, M.H.H.; White, J.-S.S. Generalized linear mixed models: A practical guide for ecology and evolution. Trends Ecol. Evol. 2009, 24, 127-135. [CrossRef] [PubMed]

25. Zuur, A.F.; Ieno, E.N.; Walker, N.; Saveliev, A.A.; Smith, G.M. Mixed Effects Models and Extensions in Ecology with R; Springer: New York, NY, USA, 2009.

26. Bates, D.; Maechler, M.; Bolker, B.; Walker, S. Fitting linear mixed-effects models using LME4. J. Stat. Softw. 2015, 67, 1-48. [CrossRef]

27. Pisapia, C.; Burn, D.; Yoosuf, R.; Najeeb, A.; Anderson, K.D.; Pratchett, M.S. Coral recovery in the central Maldives archipelago since the last major mass-bleaching, in 1998. Sci. Rep. 2016, 6. [CrossRef] [PubMed]

28. McCook, L.J.; Ayling, T.; Cappo, M.; Choat, J.H.; Evans, R.D.; De Freitas, D.M.; Heupel, M.; Hughes, T.P.; Jones, G.P.; Mapstone, B.; et al. Adaptive management of the Great Barrier Reef: A globally significant demonstration of the benefits of networks of marine reserves. Proc. Natl. Acad. Sci. USA 2010, 107, 18278-18285. [CrossRef] [PubMed]

29. Messmer, V.; Pratchett, M.S.; Hoey, A.S.; Tobin, A.J.; Coker, D.J.; Cooke, S.J.; Clark, T.D. Global warming may disproportionately affect larger adults in a predatory coral reef fish. Glob. Chang. Biol. 2016. [CrossRef] [PubMed]

30. Zajac, R.N. Sublethal predation on Polydora cornuta (Polychaeta, Spionidae)-Patterns of tissue loss in a field population, predator functional response and potential demographic impacts. Mar. Biol. 1995, 123, 531-541. [CrossRef]

31. Barrios, J.V.; Gaymer, C.F.; Vasquez, J.A.; Brokordt, K.B. Effect of the degree of autotomy on feeding, growth, and reproductive capacity in the multi-armed sea star Heliaster helianthus. J. Exp. Mar. Biol. Ecol. 2008, 361, 21-27. [CrossRef]

32. Maginnis, T.L. The costs of autotomy and regeneration in animals: A review and framework for future research. Behav. Ecol. 2006, 17, 857-872. [CrossRef]

33. Bernardo, J.; Agosta, S.J. Evolutionary implications of hierarchical impacts of nonlethal injury on reproduction, including maternal effects. Biol. J. Linn. Soc. 2005, 86, 309-331. [CrossRef]

34. Caballes, C.F.; Pratchett, M.S.; Kerr, A.M.; Rivera-Posada, J.A. The role of maternal nutrition on oocyte size and quality, with respect to early larval development in the coral-eating starfish, Acanthaster planci. PLoS ONE 2016, 11, e0158007. [CrossRef]

35. Pearson, R.G.; Endean, R. A preliminary study of the coral predator Acanthaster planci (L.) (Asteroidea) on the Great Barrier Reef. Fish Notes 1969, 3, 27-68.

36. Stump, R.J.W. An Investigation to Describe the Population Dynamics of Acanthaster planci (L.) around Lizard Island, Cairns Section, Great Barrier Reef Marine Park; CRC Reef Research Centre: Townsville, Australia, 1996.

37. Scharf, F.S.; Juanes, F.; Rountree, R.A. Predator size-prey size relationships of marine fish predators: Interspecific variation and effects of ontogeny and body size on trophic-niche breadth. Mar. Ecol. Prog. Ser. 2000, 208, 229-248. [CrossRef]

38. Berglund, A.; Rosenqvist, G. Reproductive costs in the prawn Palaemon adspersus: Effects on growth and predator vulnerability. Oikos 1986, 46, 349-354. [CrossRef]

39. Nordström, M.C.; Aarnio, K.; Törnroos, A.; Bonsdorff, E. Nestedness of trophic links and biological traits in a marine food web. Ecosphere 2015, 6, 161. [CrossRef]

40. Fuiman, L.A. The interplay of ontogeny and scaling in the interactions of fish larvae adn their predators. J. Fish Biol. 1994, 45 (Suppl. SA), 55-79. [CrossRef] 
41. Lundvall, D.; Svanbäck, R.; Persson, L.; Byström, P. Size-dependent predation in piscivores: Interactions between predator foraging adn prey avoidance abilities. Can. J. Fish. Aquat. Sci. 1999, 56, 1285-1292. [CrossRef]

42. McClanahan, T.R.; Muthinga, N.A. Patterns of predation on a sea urchin, Echinometra mathei (de Blainville), on Kenyan coral reefs. J. Exp. Mar. Biol. Ecol. 1989, 126, 77-94. [CrossRef]

43. Ling, S.D.; Johnson, C.R.; Frusher, S.D.; Ridgway, K.R. Overfishing reduces resilience of kelp beds to climate-driven catastrophic phase shift. Proc. Natl. Acad. Sci. USA 2009, 106, 22341-22345. [CrossRef] [PubMed]

44. Wilmes, J.; Matthews, S.; Schultz, D.; Messmer, V.; Hoey, A.S.; Pratchett, M.S. Modelling growth of juvenile crown-of-thorns starfish (0+ year cohort) on the northern Great Barrier Reef. Diversity 2017, 9, 1. [CrossRef]

45. Svensson, I. Reproductive costs in two sex-role reversed pipefish species (Sygnathidae). J. Anim. Ecol. 1988, 57, 929-942. [CrossRef]

(C) 2017 by the authors. Licensee MDPI, Basel, Switzerland. This article is an open access article distributed under the terms and conditions of the Creative Commons Attribution (CC BY) license (http:/ / creativecommons.org/licenses/by/4.0/). 